\title{
¿El país de los cuatro primeros? El problema del pragmatismo y los factores materiales en los estudios sobre la relación Chile-China
}

The Country of the 'Four Firsts'? The Problem of Pragmatism and Material Factors in the Literature about Chile-China Relations

\author{
Claudio Coloma Rojas \\ Universidad de Essex, Reino Unido \\ claudio_coloma@hotmail.com
}

\begin{abstract}
Resumen
El artículo pasa revista al uso del concepto de pragmatismo y la causalidad de los factores materiales en la literatura sobre las relaciones Chile-China. Se cuestiona el rol de estos elementos en la constitución de Chile como el país pionero para China en América Latina. Uno de los principales hallazgos es que el pragmatismo, como significante central de enfoques materialistas que abogan por la causalidad de las complementariedades económicas, ha sido despojado de sus orígenes como una idea auto-reportada y reificado como una condición objetiva de la relación. Sin embargo, el uso del pragmatismo es problemático cuando la literatura no puede fijar la frontera entre éste y la ideología, especialmente cuando aborda temas como la creencia en el libre comercio. El artículo concluye que cuando se articulan elementos materiales e ideales independientemente de los mecanismos causales del positivismo empírico, el estudio de las relaciones Chile-China es un campo ontológico y empírico vasto por explorar.
\end{abstract}

Palabras clave: Pragmatismo; factores materiales; factores idealistas; relación ChileChina; pionero.

\section{Abstract}

The paper takes stock of the use of the concept of pragmatism and the causality of material factors in the literature about Chile-China relations. It questions the role of these elements in the constitution of Chile as China's Latin American pioneer. One of the findings is that pragmatism, understood as the key signifier of works which rely 
on material causal mechanisms, has been stripped from its origins as a self-reported idea and reified as a taken-for-granted idea. However, the use of pragmatism is problematic since the literature is not able to establish the frontier between this concept and ideology, particularly when addressing issues such as the belief in free trade. It concludes that the issue of Chile-China relations is a vast empirical and ontological field to be explored when both material and idealist factors are brought to the fore regardless the causal mechanisms of empirical positivism.

Keywords: Pragmatism; material factors; idealist factors; Chile-China relationship; Pioneer.

\section{Introducción}

En 2005, Chile se convirtió en el primer país del mundo en firmar un tratado de libre comercio individualmente con China. Gracias a este hecho, la relación sinochilena fue considerada como el modelo de lo que este país asiático buscaba replicar con el resto de los países latinoamericanos, sedimentando la idea de ser un país pionero. La pregunta que surge entonces es ¿por qué Chile es el país pionero para China en América Latina?

Una considerable cantidad de autores ha intentado responder esta pregunta apelando a causas materiales tales como la complementariedad económica que hay entre la demanda china y los recursos naturales chilenos (Dingemans, 2014; Artaza, 2007; Labarca, 2012; Zhang, 2006). Esto a su vez ha llevado a algunos a afirmar que el pragmatismo ha sido el elemento central en la constitución de esta relación (Ross, 2007a; Rodríguez, 2011; Errazuriz, 2006). Incluso, investigaciones más recientes que han estudiado ciertos factores no materiales reafirman, paradójicamente, el rol dominante de la noción materialista del pragmatismo (Labarca, 2012; 2015).

Sin embargo, el uso del concepto de pragmatismo y la creencia en el principio positivista de la causalidad de los factores materiales son problemáticos. Las diferentes formas de aplicar el pragmatismo generan visiones contrapuestas, a veces confusas, acerca de la forma y el momento en que la relación se volvió pragmática. Este problema aparece especialmente cuando los textos relacionan este concepto con los procesos de reformas económicas paralelas que ambos países comenzaron a implementar desde la segunda mitad de los años setenta. Varios autores sugieren que el pragmatismo es la ausencia de ideología; sin embargo, las reformas económicas son llevadas a cabo por actores sociales que no pueden desafectarse de sus ideologías al momento de poner en práctica sus tecnologías. La tecnocracia, en otras palabras, da significado a la causalidad de los factores materiales de acuerdo a las prácticas con las que intenta hegemonizar los espacios donde participa. 
Más que proponer una nueva aproximación hacia el pragmatismo o una nueva ontología, este artículo analiza el uso que la literatura ha dado a este concepto y su articulación con la causalidad de los factores materiales. La pregunta que busca responder es ¿cuáles son las principales explicaciones que la literatura especializada ha formulado para dar sentido al carácter pionero de la relación Chile-China? Para ello, se realiza una vasta revisión bibliográfica de textos publicados desde mediados de los años ochenta en adelante.

En la investigación de esta revisión bibliográfica se encontraron más fuentes chilenas que chinas o de otra nacionalidad. En total fueron analizados treinta y un textos escritos por chilenos y doce textos escritos por chinos. Esta diferencia puede explicar por qué en la literatura se ha prestado mayor atención a la política exterior y a las reformas económicas chilenas. Aunque fue posible encontrar un alto número de artículos chinos sobre Chile (43), seis de ellos solamente son acerca de la relación Chile-China. Así, la mayoría de estos artículos aborda el modelo económico chileno como tal o estudiando algún aspecto de éste, como el sistema de pensiones o las políticas sociales. En la medida en que esta investigación trata sobre las relaciones Chile-China, se dio atención prioritaria a los textos correspondientes, así como también a algunos textos que estudian la relación China-América Latina, tales como la antología del pensamiento social chino sobre América Latina, publicada por Wu (ed., 2018).

Uno de los hallazgos de este estudio es que el pragmatismo, en vez de ser un enfoque disciplinariamente constituido, emergió como una auto-interpretación que algunos autores articularon para describir la relación. Luego, la misma se usó repetitivamente hasta el punto de ser reificada como la perspectiva oficial para abordar este tema, tanto académica como diplomáticamente. En este sentido, el trabajo de una autora en particular es revelador: "Los círculos académicos chilenos han caracterizado al Asia Pacífico, y dentro de esto a China, como una oportunidad económica desde los '90 en adelante influidos por la preponderancia neoliberal de la política exterior chilena” (Labarca, 2012: 161-162)1. Sin embargo, la reificación del pragmatismo ha conllevado a enfoques explicativos insatisfactorios. El texto concluye que el carácter pionero de la relación puede ser explicado más satisfactoriamente tomando en cuenta tanto los elementos materiales como los ideales; además, dentro de estos últimos, los elementos ideológicos juegan un rol crucial en dicha tarea.

El artículo comienza describiendo la idea de 'Chile como el país pionero de China en América Latina' y la forma en que los enfoques que denominamos como materialistas (por su énfasis en el pragmatismo y los recursos naturales) articulan esta idea. En la siguiente parte, se apunta a las inestabilidades e inconsistencias del

\footnotetext{
1 Traducción del autor.
} 
discurso materialista cuando éste revela su irreducible dimensión idealista. Se presta especial atención a aquellos momentos cuando el discurso del pragmatismo aparece incapaz de fijar la frontera entre la ideología de los tecnócratas y su influencia en las políticas exteriores de ambos países. La cuarta parte examina algunas promisorias incursiones que denominamos como idealistas (por su énfasis en el estudio de las ideas sociales), dentro de las cuales se observa que, a pesar del reconocimiento a la importancia de los factores no materiales, estos son finalmente subordinados a las consideraciones materialistas. La última sección retoma la discusión de la relación entre factores materiales e ideales en pos de justificar la necesidad de incluir a los elementos ideológicos para explicar el carácter pionero de la relación.

\section{Chile como el país de los 'cuatro primeros'}

Como si fuera una metáfora china, la literatura suele usar la denominación de "los cuatro primeros" para resaltar que Chile ha sido el primer país para China en cuatro oportunidades especialmente significativas (Ampuero, 2016; Toloza (ed.), 2015; Errázuriz, 2006; Heine, 2006; Labarca, 2012; Li, 2011; Sun, 2011; Yang, 2011).

1. Chile fue el primer país sudamericano en reconocer a la República Popular China como la única y legítima China, a expensas de retirar el reconocimiento que había hecho previamente a la República China de Taiwán (1970).

2. Chile fue el primer país latinoamericano en apoyar formalmente el requerimiento chino de ser miembro de la Organización Mundial de Comercio (1999).

3. Chile fue también el primero en Latinoamérica en reconocer formalmente a China como una economía de mercado (2004).

4. Chile fue el primer país individual en el mundo en firmar un TLC con China (2005).

Algunos autores señalan que estos hitos no solo representan los cimientos de la relación, sino que también la orientación comercial que ésta ha tenido desde los años noventa (Moreno, 2011; Rehner y Montt, 2013). Labarca afirma, por ejemplo, que el discurso de los primeros es un rasgo esencial, del cual la parte chilena suele sacar ventajas a su favor. Haber sido el primer país en establecer lazos diplomáticos funciona como un "caballito de batalla" que "ha proveído la percepción de tener una asociación con un estatus privilegiado", favoreciendo sobretodo la cooperación en el ámbito comercial (Labarca, 2012: 152-153).

Entre los autores chinos, la idea de que Chile es el país pionero para China refleja en cierto grado las expectativas sobre las relaciones de este último con el resto de la región. Por ejemplo, en uno de los artículos de la antología del pensamiento social chino sobre América Latina, Niu Haibin retrata lo que Chile 
significa para China en el escenario de la Comunidad de Estados Latinoamericanos (CELAC):

La Segunda Reunión Ministerial del Foro China-CELAC se realizó en Chile en enero de 2018, y hay que recordar que Chile es el principal socio comercial de China en América Latina, y también un pionero en el desarrollo de las relaciones con China en muchas áreas, como el libre comercio y la asociación estratégica. Por eso, es previsible que China y su socio estratégico en América Latina sean la fuerza clave que impulse la profundización del Foro China-CELAC (Niu, 2018: 229).

Sin embargo, cabe notar cómo ciertos autores observan que el discurso de "los cuatro primeros" no refleja el real estatus diplomático que China dio a Chile durante las décadas de los noventa y dos mil (Bernal-Meza, 2012; Dingemans, 2014; Labarca, 2012; Montalva y Navia, 2007). Si consideramos, por ejemplo, la forma en que Domínguez et al. (2006) describen el criterio chino para jerarquizar las relaciones con otros estados, Chile fue solo un socio cooperativo (segunda clase) durante todo ese tiempo, mientras que Brasil, Argentina y Venezuela eran socios estratégicos (primera clase). Así, para Labarca (2012), el estrecho alcance de la relación gatilla el pragmatismo por sobre los compromisos ideológicos. Para autores como Zhang (2006) y Wu (2011), en tanto, Chile no tiene posibilidades de ser un socio estratégico debido a su tamaño.

Es en este contexto que la literatura tiende a articular la noción de ser pionero con el discurso del pragmatismo, el cual trae al frente a los factores materiales como el principal elemento explicativo de la relación.

\section{El discurso del pragmatismo y la causalidad de lo material}

Una considerable cantidad de textos caracteriza la relación sino-chilena como pragmática (Ampuero, 2016; Toloza (ed.), 2015; Bernal-Meza, 2012; Dingemans, 2014; Labarca, 2012; Matta, 1991; Montalva y Navia, 2007; Pérez Le-Fort, 2006; Rodríguez, 2011; Ross, 2007a; 2007b). El concepto de pragmatismo se usa esencialmente para representar a una relación desideologizada, que está centrada en políticas tecnocráticas que sacan ventajas de las complementariedades económicas. Ciertos autores chilenos enfatizan este punto elocuentemente:

Aquí se advierte el predominio del pragmatismo por sobre cualquier otro valor: un mercado de 1.300 millones de personas y un oferente tan competitivo de bienes manufacturados (Gilpin, 2000), parecen ser la base de la diferenciación. En esta dirección la política chilena ha sido 
coherente al plantearse, fundamentalmente, objetivos bilaterales, cuya principal satisfacción es cuantitativa (Ross, 2007a: 123).

Por el lado chino, Cui Shoujun y Zhang Zheng explican que el pragmatismo es parte de la política exterior de China hacia América Latina, la cual se enfoca en el comercio, la inversión, infraestructura y capacidad productiva:

Mientras que el comercio, la inversión y la cooperación financiera entre China y ALC siguen creciendo, la infraestructura y la cooperación en capacidad productiva se han convertido en el nuevo motor que impulsa el desarrollo pragmático de las relaciones entre China y ALC (Cui y Zhang, 2018: 267).

Es en el marco de estas definiciones que la literatura ha prestado mayor atención a la firma del TLC y sus causas (Artaza, 2007; Heine, 2006; Labarca, 2012; Zhang, 2006). Al respecto, la explicación que más se repite es que el TLC fue el resultado de las complementariedades económicas, las cuales están determinadas por la demanda china de recursos naturales (Errázuriz, 2006; Heine, 2006; Labarca, 2012; Zhang, 2006). Es decir, el TLC sería el resultado del apetito chino por el cobre chileno (Artaza, 2007; Dingemans, 2014; Rehner y Montt, 2013). En su artículo "El entendimiento sobre el Tratado de Libre Comercio entre Chile y China", Zhang Xinsheng señala que

Las grandes complementariedades económicas y el vasto espacio de cooperación entre China y Chile constituyen un importante potencial para desarrollar las relaciones económico-comerciales entre ambos en el futuro [... China] tiene grandes necesidades de recursos naturales, así como de productos agropecuarios y de la pesca. En cambio, Chile, pese a que su economía es relativamente pequeña, tiene una elevada competitividad internacional $\mathrm{y}$, sobre todo, cuenta con cobre y otros productos mineros y agrícolas muy necesarios para China, lo que demuestra la complementariedad económico-comercial entre ambos (Zhang, 2006: 115).

A su vez, este tipo de explicaciones llevan a la suposición de que las complementariedades económicas gatillan acciones pragmáticas. En este sentido, Yu Yunxia introduce su artículo "Comentarios sobre el Tratado de Libre Comercio entre China y Chile” destacando el carácter pragmático de este acuerdo:

El TLC entre China y Chile, firmado el 18 de noviembre de 2005, tendrá un gran y positivo impacto sobre las relaciones bilaterales de 
estas dos naciones [...] este acuerdo pragmático hará mejor uso de la complementariedad de estas dos naciones (Yu, 2006: 1).

Aunque rara vez se señala explícitamente, varios textos tienden a concebir el pragmatismo como la ausencia de ideología, por cuanto la relación no buscaría compromisos políticos y porque sus mecanismos de cooperación que promueven el libre comercio serían, paradójicamente, prácticas no ideológicas. Esto se expresa de diversas formas. Algunos autores contrastan el carácter desideologizado y pragmático de la relación actual con el énfasis dado a la ideología en las décadas anteriores (Errázuriz, 2006; Dingemans, 2014; Schmidt, 2011). Otros lo comparan con los regímenes populistas de izquierda sudamericanos (y por tanto ideologizados) de los años dos mil (Pérez Le-Fort, 2006). También hay quienes contrastan el carácter ideológico de la política exterior china de la era de Mao con la desideologización que caracterizaría a la política exterior de los líderes actuales (Bernal-Meza, 2012; Rodríguez, 2011).

Sin embargo, el pragmatismo es un concepto problemático. En primer lugar, los estudios no han definido el significado de pragmatismo ni han evaluado esta categoría cuando la asocian con el acento comercial de la relación. Segundo, en algunos casos este vacío conlleva a la formulación de explicaciones insatisfactorias. Un caso evidente es cuando se intenta explicar cómo la relación se volvió pragmática en el contexto de las reformas económicas paralelas. Tercero, en la medida en que los estudiosos han persistido en repetir el uso del pragmatismo como un significante central que da sentido a la relación, vemos que este elemento es despojado de sus orígenes como una auto-interpretación sujeta a la contingencia del contexto desde el cual el autor(a) desarrolló su análisis. En la siguiente parte profundizaremos cada uno de estos puntos.

\subsection{Pragmatismo como un concepto sin definición}

Como los estudios no se han abocado a definir qué es pragmatismo, el uso de este significante es diverso. Algunos textos lo ocupan indistintamente para caracterizar la política exterior de un país hacia el otro o bien para referirse a la relación como un todo (Labarca, 2012; Matta, 1991; Montalva y Navia, 2007; Ross, 2007a).

Además, este concepto no solo ha sido usado con pretensiones teleológicas para describir la historia de los lazos diplomáticos, sino que también para oponerlo a la ideologización de los tiempos de Allende o referirse a decisiones particulares para superar situaciones complejas. Mientras autores como Matta concluyen que la flexibilidad y el pragmatismo han sido "las permanentes características observadas en la relación" desde sus inicios (1991: 347), Schmidt sostiene que la relación 
durante los años de Allende fue "profundamente ideológica" (2011: 3065); por su parte, Jiang distingue las ocasiones puntuales que han ameritado llevar a cabo acciones pragmáticas de otros periodos de "identificación política y económica" (2001: 12).

Hay algunos textos en donde se sugiere que el pragmatismo puede ser ejercido por cada país (Pérez Le-Fort, 2006; Dingemans, 2014; Ampuero, 2016). Rodríguez, por ejemplo, explicita que el pragmatismo de Chile hacia China es algo diferente al pragmatismo de China hacia Chile. El pragmatismo de China prevaleció por sobre la solidaridad socialista cuando ésta no rompió relaciones con Chile después del golpe de estado en 1973 (Rodríguez, 2011: 4732). Luego, el pragmatismo de Chile se impuso al anticomunismo de la dictadura cuando éste se acercó a China como un nuevo socio comercial en 1978 (Rodríguez, 2011: 4732). Desde esta perspectiva, sería plausible sostener que la interacción de dos políticas exteriores pragmáticas constituiría una relación pragmática, lo cual habría sucedido entre el derrocamiento de Allende en 1973 y el inicio de las reformas económicas (alrededor de 1978).

En cambio, hacer este mismo tipo de afirmación es mucho más complejo después de que las reformas económicas se implementaron. Por ejemplo, en el mismo texto, Rodríguez afirma que la relación, después de un periodo de "pragmatismo absoluto" (1973-1978), vivió un periodo de "mayor pragmatismo y, por lo tanto, de mayor sintonía" (1978-1990). De acuerdo a esta autora, las causas de esta extraña situación de haber pasado desde un estado de pragmatismo absoluto a otro de mayor pragmatismo fueron principalmente los procesos paralelos de apertura económica y la consecuente desideologización de los líderes chinos (Rodríguez, 2011: 4809-4854).

Con respecto a esta desideologización, Bernal-Meza (2012) sostiene que en China el pragmatismo ha sido más evidente desde los años dos mil debido a la pérdida de la carga ideológica en la política exterior china; de ahí que "el motor de la acción exterior ha sido la promoción de los intereses nacionales de China y no los temas ideológicos" (Bernal-Meza, 2012: 66).

Sin ser conclusivo, la suposición de la desideologización contrasta con algunos estudios que han abordado el tema de la ideología en el contexto de las reformas económicas no solo en Chile (Camargo, 2013; Garretón, 2012; Moulian, 1997; Pinedo, 1997; Kaiser, 2009) sino que también en China. Tomemos el caso de Wang Hui $(1998 ;$ 2009). Tomemos el caso de Wang Hui $(1998 ; 2009)$, quien explica que, más que experimentar un fenómeno de desideologización, diferentes ideologías estuvieron interactuando entre los setenta y los noventa, tales como el maoísmo, el socialismo de las reformas, el socialismo humanista y las ideologías de lo que él denomina como el Movimiento de la Nueva Ilustración. Según Wang, estas ideologías 
tuvieron un significativo impacto en todo el Estado chino, incluyendo la política exterior. Por su parte, Xu Youyu (2003) describe el debate entre liberales y lo que él define como la Nueva Izquierda en temas como la relación Estado-mercado, la participación de China en los mercados globales y el concepto de la modernidad. De hecho, Xu destaca que este tipo de debate no se veía en China desde antes de 1949.

En su artículo "Entendiendo las relaciones de China con los países de América Latina y el caribe. Notas de una investigación”, Harris apunta que:

Como Roland Boer (2014) argumenta, "para hacer sentido de la China moderna, tú simplemente no puedes ignorar el marxismo." Mientras varios observadores extranjeros "continúan ignorando el marxismo en China" como "una ideología represiva e inadecuada o como palabras vacías en las cuales nadie más cree," esto es, como Boer apunta, "un gran error y arriesga en desatender en lo que claramente es uno de los más importantes factores para entender China." Boer sostiene que la mayoría de los observadores extranjeros no entienden el marxismo chino y como resultado tienden a ignorar o desatenderlo como un factor primario en las relaciones exteriores de China (Harris, 2015: $31)^{2}$.

Como podemos ver, aunque algunos estudios encienden luces sobre las posibilidades plausibles que existen para caracterizar a la relación como pragmática en circunstancias específicas, no es posible, sin embargo, definir satisfactoriamente la forma en que el pragmatismo, o el fenómeno de la desideologización, determinan el carácter de la relación después de 1978. Lo que aparece como problemático, en otras palabras, es la relación entre pragmatismo y las reformas económicas. Resolver este problema es crucial si consideramos que la imagen de Chile como el pionero de China en la región se basa esencialmente en el apoyo chileno al ingreso de China a la OMS y en el TLC; hechos que por lo demás se consideran como expresión de pragmatismo.

\subsection{Pragmatismo y reformas económicas}

La cuestión de cómo y cuándo la relación se volvió pragmática es un tema que amerita ser problematizado debido a las incongruencias que observamos al contrastar diferentes puntos de vista. Por un lado, hay autores que señalan que la relación ha sido pragmática desde su misma fundación en 1970 (Matta, 1991; Labarca, 2012). Por ejemplo, Labarca afirma que la relación en sus inicios "no es considerada como ideológica [...] debido a las diferencias políticas entre ambos

\footnotetext{
2 Traducción del autor.
} 
regímenes socialistas" (2012: 141). Por el otro lado, autores como Errázuriz (2006) y Schmidt (2011) sugieren que la relación en sus inicios no fue pragmática, sino que ideológica o inclinada hacia el simbolismo político.

Pero hay un contraste de visiones que es menos evidente a simple vista, aunque cuando sale a la luz, aparece como un asunto con consecuencias explicativas importantes. Se trata de la relación entre pragmatismo y las reformas paralelas de liberalización económica que Chile y China comenzaron a implementar desde la segunda mitad de los años setenta. Este problema ya lo habíamos advertido preliminarmente cuando se afirmaba que había más pragmatismo que pragmatismo absoluto. Por un lado, pragmatismo puede ser entendido como una etapa temporal previa a las reformas económicas. Por el otro, pragmatismo sería la consecuencia misma de las reformas económicas.

En el primer caso, Navia y Montalva afirman que el pragmatismo en la relación prevaleció después del golpe de Estado en contra de Allende, dando paso a una relación fría o distante. Fue al término de este periodo en que

China inició sus reformas económicas en 1978. Chile también estaba emprendiendo reformas orientadas a abrir mercados y promover el libre comercio. Ambos países adoptaron reformas similares al mismo tiempo. A pesar de estar internacionalmente aislados, el haber abrazado Chile y China las políticas del libre mercado hizo más fácil para los dos gobiernos encontrar un terreno común, a pesar de las aparentemente inconmensurables diferencias entre un gobierno comunista y uno anticomunista (Montalva y Navia, 2007: 7)3 .

Siguiendo este argumento, el pragmatismo fue una especie de etapa previa al "terreno común" que ambos países hallaron con las reformas económicas. A su vez, este terreno común no es una caja negra, vacía de contenido ideológico; por el contrario, es una forma de representar una manera más fácil para estrechar los lazos a través de la creencia compartida en el libre comercio. Desafortunadamente, estos autores no indagan más en la relación entre las reformas paralelas de liberalización económica y la constitución del así llamado terreno común.

Contrario a la posición de Navia y Montalva, otros autores sostienen abiertamente que las reformas económicas paralelas hicieron que la relación se volviera pragmática (Errázuriz, 2006; Rodríguez, 2011; Ross, 2007a, 2007b). Por ejemplo, Ross sostiene que, a pesar de haber tenido grandes diferencias ideológicas, ambos países "vivieron procesos históricos de organización política y económica relativamente equivalentes y simultáneos, lo que les permitió vincularse pragmáticamente y convertirse en socios económicos" (Ross, 2007a: 120).

3 Traducción del autor. 
Cabe notar que Ross desarrolla este argumento estudiando la política exterior chilena en vez de las políticas exteriores de Chile y China en conjunto (Ross, 2007a; Ross, 2007b: 82-86). En este contexto, él explica que los economistas chilenos ganaron influencia en la política exterior, hasta el punto de que ésta fue subordinada a los objetivos económicos nacionales. Así, por ejemplo, menciona la creación de la Dirección General de Relaciones Económicas de la cancillería en 1978 (Ross, 2007b: 61). Luego, sostiene que el triunfo de la tecnocracia pragmática sobres las visiones diplomáticas tradicionales hizo que la política exterior chilena fuera dominada por un pragmatismo total (Ross, 2007b: 62).

Hasta aquí hemos visto que no es posible determinar cuándo y cómo la relación se volvió pragmática. Es decir, no hay consenso para determinar si el pragmatismo es una condición permanente que está desde el establecimiento de los lazos diplomáticos, ni tampoco para determinar si las reformas económicas paralelas son una fuente del pragmatismo en la relación. Tampoco estamos en condiciones de hacer afirmaciones conclusivas con respecto a la dimensión ideológica de la relación. El problema se acrecienta cuando observamos que se induce que la relación es pragmática a partir de la interpretación que se hace de la política exterior de una de las dos partes de la relación. Todo esto nos conduce a explorar si más que una condición objetiva de la relación, el pragmatismo es una interpretación que se ha dado por sentada.

\section{La sedimentación del pragmatismo en los textos académicos}

El uso del pragmatismo como una idea que se da por sentada es el resultado de un proceso en el cual la literatura sobre la relación Chile-China ha experimentado una transición desde el desarrollo de estudios de tipo histórico y descriptivo (Jiang, 2001; Matta, 1991; Muñoz, 1986; Soto, 1998)4 hacia la necesidad de desarrollar investigaciones de carácter más científico-social (Dingemans, 2014; Labarca, 2012). En este proceso, los primeros estudios se convierten en un tipo de fuente de las futuras investigaciones. Vale decir, un buen número de investigaciones usa estos primeros textos como parte de su material bibliográfico para citar tanto hechos históricos como auto-interpretaciones.

Considerando las auto-interpretaciones, la del pragmatismo es una de las que más se ha reproducido a lo largo de la última década. Así, en los textos más

\footnotetext{
${ }^{4}$ Antes de estas fechas no encontramos publicaciones de autores chinos, lo cual no quiere decir que en China no se haya estado estudiando el tema de Chile. En efecto, la Academia China de Ciencias Sociales tiene publicado un buen número de publicaciones (al menos 27) sobre Chile. En suma, si bien es posible que haya más trabajos al respecto, lo que cabe destacar es que en los ochenta y noventa el tema Chile-China no es relevante para la disciplina de los estudios internacionales ni en Chile, ni en China, ni en otras partes del mundo.
} 
tempranos (Matta, 1991; Pérez Le-Fort, 2006; Domínguez, 2006; Muñoz, 1986) este concepto aparece como una idea auto-reportada, para luego ser citada en futuras investigaciones (Ampuero, 2016; Dingemans, 2014; Labarca, 2012; 2015; Rodríguez, 2011; Ross, 2007a; 2007b). De esta forma, se lleva a cabo un proceso de reificación del pragmatismo, que con el tiempo termina asumiéndose como una condición objetiva de la relación.

Un caso paradigmático de la sedimentación del pragmatismo en la literatura comienza con el artículo de Matta, publicado en 1991. Este autor sugiere que Salvador Allende justificó razones políticas y pragmáticas, además de razones ideológicas y económicas para establecer relaciones con China. De hecho, este es el punto de partida que lleva a Matta a concluir que la relación ha sido pragmática y flexible desde el inicio. La fuente primaria que el autor usa para apoyar esta observación es el Mensaje Presidencial al Congreso Nacional de 1971; sin embargo, ni el Mensaje Presidencial (1971a) ni el Informe de la Presidencia al Congreso Nacional (1971b) indican que la política exterior hacia China haya sido pragmática. En otras palabras, que la decisión de establecer relaciones con China sea pragmática no es un hecho, sino que una interpretación que hace el autor. Además, el hecho de apuntar el estilo pragmático de Chile no quiere decir necesariamente que la relación en sí sea pragmática.

Es necesario señalar a modo de paréntesis que, en esos años, este tipo de interpretación no era una excepción, sino más bien una especie de norma para caracterizar a la política exterior del gobierno de Allende. Al respecto, en su artículo sobre pragmatismo e ideología en la política exterior chilena, Fermandois (1985: 169) señala que "se ha convertido -en gran parte de la literatura especializada- en una afirmación recurrente el sostener el sustancial "pragmatismo" de su política internacional [léase la Unidad Popular] en contradicción con su estrategia política interna y con la política internacional del gobierno que le sucedió". De hecho, esta "afirmación recurrente" en relación al gobierno de Allende no solo está presente en obras tempranas como la de Heraldo Muñoz (1986) y el mismo Matta, sino que también está presente más tarde en artículos como los de Ross (2007a) y Montalva y Navia (2007).

Desde la publicación del artículo de Matta, los estudios que fueron citando este texto para afirmar que la relación es pragmática fueron progresivamente sedimentando esta idea, convirtiéndola en una categoría óntica (Ampuero, 2016: 45; Rodríguez, 2011; Toloza, ed., 2015; Ross, 2007b). Por ejemplo, en un artículo del año 2011, Rodríguez concluye que:

Pues como bien señala Javier Matta (1991: 347), los vínculos diplomáticos entre Chile y la RPCh, estuvieron atravesados por el pragmatismo y la flexibilidad. En otras palabras, existieron intereses 
internos que, más allá de la orientación ideológica que los separaba, los llevó a mantener los lazos creados desde 1970 (Rodríguez, 2011: 174).

Hay otro caso de sedimentación del pragmatismo que parte con un texto que concluye que la política exterior chilena posee un estilo pragmático; luego, un segundo texto que cita al anterior para afirmar que no solo la política exterior chilena es pragmática, sino que también la relación Chile-China. Finalmente, hay un tercer texto que se apoya en el segundo para afirmar que la política exterior de China hacia Chile es pragmática.

Primero, el libro de Heraldo Muñoz sobre la política exterior de la dictadura militar argumenta que en la cancillería chilena coexistieron incómodamente dos estilos diplomáticos, el estilo ideológico-pretoriano de los militares y el civilpragmático impulsado por los tecnócratas neoliberales (Muñoz, 1986: 44-47). Luego, Ross contesta la tesis de Muñoz argumentando que, más que una coexistencia incómoda, hubo una cohabitación de estilos que él denomina como el estilo pretoriano-pragmático, el cual significa la consumación del pragmatismo en la política exterior chilena. Es en base a esta tesis que Ross plantea que la relación Chile-China es pragmática (Ross, 2007a,: 120-121; 2007b: 83-84). Finalmente, tenemos el artículo de Dingemans sobre la estrategia de Chile hacia el este de Asia, el cual cita a Ross, junto con un artículo sobre política exterior chilena de Fermandois, para apuntar al pragmatismo de China (y Japón) hacia Chile: "Interesantemente, el pragmatismo ideológico había dominado las políticas exteriores china [23] y japonesa [24] también" (Dingemans, 2014: 70)5.

Hasta aquí hemos visto cómo la literatura caracteriza la relación bilateral como pragmática y los problemas que este concepto conlleva. En este sentido, aún cuando el argumento que sostiene que la liberalización económica de un país gatillaría el pragmatismo podría parecer convincente (mas no conclusivo), éste no explica por qué la liberación económica paralela de ambos países es la causa del pragmatismo en la relación.

\section{Sensibilidades idealistas dentro de enfoques materialistas}

Aunque la literatura suele traer al frente a los factores materiales como una precondición del pragmatismo para explicar los acuerdos pioneros entre Chile y China, en ella también se observa -como dijo Cassels (1996) en Ideología y Relaciones Internacionales- cierta preocupación consciente o (lo más probable) inconsciente sobre los elementos no materiales de la relación.

\footnotetext{
5 Traducción del autor.
} 
Por ejemplo, Alfonso Dingemans (2014) reafirma el carácter pragmático de la política exterior chilena y el rol de los recursos naturales en la asociación sinochilena. No obstante, también hace algunos planteamientos que no necesariamente corresponderían a una visión materialista pragmática. Por ejemplo, este autor señala que las políticas implementadas por los Chicago Boys: "llevaron a una creciente 'economización' de la política exterior de Chile en general y a una excesiva concentración en el acceso a los mercados de su política comercial. La liberalización unilateral de la economía chilena mostró su firme creencia en el libre comercio" (Dingemans, 2014: 71)6.

De manera similar, Heine (2006: 146) define que la política exterior chilena está "basada en una estrategia dirigida por una política de exportaciones que se apoya en una economía abierta, una gestión macroeconómica sensata e instituciones fuertes". Según este autor, es debido a estas características que ningún otro país en el mundo ha firmado tantos tratados de libre comercio como Chile.

Si bien esta preocupación por los factores ideales no siempre se expresa explícitamente, podemos identificar dos tipos de ideas que nos ayudan a dar sentido a esta sensibilidad. En primer lugar, la idea de la continuidad de la política comercial neoliberal de Chile desde la dictadura militar hasta los gobiernos democráticos. En segundo lugar, la idea de que existe un fenómeno paralelo de reformas de liberalización económica iniciado en la segunda mitad de los años setenta.

\subsection{La continuidad de la política comercial chilena}

Un buen número de textos suele relacionar el carácter abierto de la economía chilena con la continuidad que esta política ha tenido desde la dictadura hasta los gobiernos democráticos. A su vez, esta continuidad sería una de las causas de los compromisos pioneros entre Chile y China (Bernal-Meza, 2012; Dingemans, 2014; Montalva y Navia, 2007; Schuschny et al, 2008).

Schuschny et al. (2008: 9-10) explican que la política comercial chilena ha sido el resultado de continuos esfuerzos llevados a cabo por diferentes gobiernos desde 1973; además, dicha continuidad habría sido crucial para la firma del TLC con China. Los autores identifican dos fases de liberación. Primero, liberación bajo un gobierno dictatorial, la cual se caracterizó por la liberación de la economía a través del sector privado y por poner en práctica dos principios: el principio de no discriminación de regímenes político-ideológicos, y el principio de neutralidad o política de eliminación del apoyo estatal a la industria nacional. Segundo, la fase de liberación bajo gobiernos democráticos, la cual tiene entre sus rasgos centrales la firma de una amplia red de acuerdos comerciales en el mundo.

\footnotetext{
${ }^{6}$ Traducción del autor.
} 
Algunos autores asocian la concentración de la política exterior chilena en el comercio durante el periodo democrático con el concepto de regionalismo abierto (Bernal-Meza, 2012; Dingemans, 2014). Este concepto apareció cuando Chile estaba buscando ser miembro de la APEC a inicios de los noventa (van Klaveren, 1997; Wilhelmy y Lazo, 1997). Wilhelmy y Lazo (1997: 6) definen regionalismo abierto como un proceso multilateral de apertura económica que no discrimina a economías que sean o no miembros de APEC. En este sentido, es interesante observar que, aún cuando el regionalismo abierto fue pensado e implementado en los noventa, su contenido es similar al principio de no discriminación que implementó la dictadura, el cual describen Schuschny et al (2008).

Una de las personas más dedicadas a desarrollar la idea de regionalismo abierto fue Alberto van Klaveren, quien ha sido una figura central en los círculos diplomáticos y académicos, especialmente en los años noventa y dos mil. Desde su posición como académico influyente y alto funcionario del Ministerio de Relaciones Exteriores, van Klaveren no solo estuvo interesado en desarrollar la idea del regionalismo abierto, sino que también en llevarla a cabo como una política de Estado. En este contexto, en su artículo "La política exterior de Chile durante los gobiernos de la Concertación (1990-2010)", van Klaveren señala que hubo una continuidad de la política del comercio exterior entre la dictadura y los gobiernos de la Concertación (van Klaveren, 2011: 155).

A partir de la continuidad de la política exterior de Chile, expresada en la similitud que hay entre el principio de no discriminación y el regionalismo abierto, podríamos problematizar si acaso el énfasis comercial de la política exterior chilena sería la sedimentación de prácticas discursivas y no el resultado de las fuerzas materiales de la economía. En tal escenario, también podríamos cuestionar si acaso es posible combinar el propósito de llevar a cabo una política exterior pragmática con el deseo de abrazar firmemente la creencia en el libre mercado. Dicho de otro modo, una tarea pendiente es comprender el fenómeno de cómo el principio de no discriminación y el regionalismo abierto simbolizan la firme creencia en el libre comercio de la elite chilena que ha estado envuelta en la formulación de la política exterior a partir de las reformas económicas iniciadas a mediados de los setenta.

\section{Reformas económicas paralelas}

Aunque el modelo de desarrollo económico chino no ha sido tan abordado como el chileno en la literatura, es posible ver algo sobre este tema a través de la noción de reformas económicas paralelas. En términos generales, este tema se formula como un elemento de la condición de países en desarrollo que Chile y China comparten y la forma en que han trazado trayectorias relativamente similares en sus 
empeños por convertirse en países modernos (Wu, 2011; Jiang, 2006; Sun, 2011; Schmidt, 2011; Uribe, 2016; Almeyda y Zhou, 1973; Kissinger y Zhou, 1973).

De acuerdo a textos chinos, la noción de procesos paralelos de desarrollo es una expresión para referirse a China en relación a toda América Latina (Ministerio de Relaciones Exteriores de la República Popular China, 2016; Harris, 2015). En este contexto, el TLC con Chile, así como también con Perú y Costa Rica, representa un modelo de mecanismo para impulsar la cooperación entre China y la región. En este contexto, Xin Xiaodai señala que, en pos de enfrentar el desafío de incrementar los lazos entre regiones subdesarrolladas, es importante que China consiga más tratados de este tipo con más países latinoamericanos (Xin, 2018: 257).

Por el lado chileno, un amplio rango de autores explica que Chile y China experimentaron procesos paralelos de desarrollo en el marco de sus reformas económicas (Bernal-Meza, 2012; Montalva y Navia, 2007; Rodríguez, 2011; Ross, 2007a, 2007b; Schmidt, 2011). Como ya mencionamos previamente, ciertos autores sugieren que las experiencias paralelas de liberalización económica gatillaron el pragmatismo en la relación sino-chilena, así como también ponen en práctica una lógica positivista de la causalidad de los factores materiales, tales como los recursos naturales para sustentar este argumento.

En contraste, otros autores sugieren que el proceso paralelo de reformas económicas generó una suerte de intersubjetividad, la cual explicaría el buen devenir de la relación. Esta intersubjetividad es planteada de diversas maneras, tales como el 'terreno común' que ya vimos con Montalva y Navia (2007), o el 'entendimiento mutuo', según plantea Jiang (2006: 31). Errázuriz, por ejemplo, lo formula de la siguiente manera: "El proceso de reforma y apertura que inició la República Popular en 1976 era coincidente con los lineamientos económicos del Gobierno militar, lo que habría mayores espacios de diálogo y cooperación” (Errázuriz, 2006: 171).

Igualmente, Rodríguez (2011: 186) señala que después de las reformas económicas, la relación experimentó el "periodo de mayor coincidencia y complementariedad [...] compartiendo las premisas liberales de la economía". Esta autora también afirma que en el contexto de la globalización económica "no hay opciones ideológicas en cuanto a la política económica estatal”.

Sin embargo, aunque en la literatura se apunte a un proceso paralelo de liberalización económica como una posible causa de tipo no material del carácter pionero de la relación Chile-China, este tema no ha merecido una atención más profunda. Ningún estudio ha explicado hasta aquí, la forma en que los procesos paralelos de reforma, en tanto que factor causal idealista, podría intensificar la asociación bilateral. Por el contrario, hemos visto que la literatura plantea este tipo de argumento dentro de descripciones de tipo materialista. Dicho de otro modo, este tipo de factor también se ha vuelto otro elemento que se da por sentado. 


\section{Aproximaciones idealistas a la relación Chile-China}

En 1998, Augusto Soto señaló que de la relación de Chile con China no solo emergen oportunidades, sino que también desafíos. Los desafíos están relacionados con la educación chilena, la tradición diplomática, el estilo occidental de hacer negocios y la reciente historia política. A continuación, cuestionó si Chile estaba listo para entender totalmente el significado e importancia del ascenso de China (Soto, 1998: 47). Si bien el objetivo de este autor no era resolver estos problemas, sí apuntó a que la cultura era el campo de estudio para encontrar las respuestas.

De igual manera, otros autores han afirmado que el primer obstáculo para mejorar los vínculos bilaterales es la falta mutua de conocimiento (Errázuriz, 2006; Rehner y Montt, 2013; Zhang, 2006). Por ejemplo, Errázuriz (2006: 176-177) sugiere que, si China y Asia son tan importantes para Chile, entonces es necesario aprender acerca de sus culturas, diversidad, mentalidades, negocios y estilos de vida. De esta manera, él concluye, sería posible entender mejor sus procesos políticos, económicos y sociales.

Este tipo de problematización idealista hacia las relaciones Chile-China indica el punto de partida para una nueva agenda de investigación; una dedicada a abordar un rango más amplio de temas que el análisis comercial en las relaciones diplomáticas. Este tipo de enfoque se expresa en los trabajos de académicas como María Montt (2014; Rehner y Montt, 2012) y Claudia Labarca (2009; 2012; 2013; 2015; Labarca y Montt, 2019). De estos, uno de los estudios más destacables es el modelo de construcción de confianza desarrollado por Labarca (2012). Este trabajo destaca no solo por ser una de las primeras investigaciones que trae al centro los factores idealistas - "soft"- para explicar la relación Chile-China, sino que también porque es el estudio más comprehensivo publicado hasta la fecha sobre este tema.

\subsection{Las variables soft de la relación Chile-China}

Labarca parte observando que la relación ha tenido que lidiar con expectativas incompletas o con la inhabilidad para hacerla florecer más allá del comercio de commodities. En este contexto, ella cuestiona las aproximaciones tradicionales de la economía política, las cuales suelen creer "que el camino de la mutua cooperación parece estar pavimentado" (Labarca, 2012: 2). Este camino habría sido pavimentado por tres elementos: primero, "las fuertes complementariedades económicas" determinadas por la demanda china de recursos naturales. Segundo, la historia común de reforma y exitosa liberalización económica. Tercero, el hecho de que Chile sea uno de "los mejores ejemplos de liberalización económica de América Latina” (Labarca, 2012: 1). 
Esta examinación crítica lleva a Labarca a plantear "la debilidad de las variables tradicionales duras"; de ahí que ella orienta su investigación hacia las variables blandas, las que define como "la dimensión mental y cultural de la realidad social” (Labarca, 2012: 4). Luego de analizar las teorías de la modernización, la autora formula un argumento en el cual combina principios constructivistas con los de la teoría liberal acerca del rol de las ideas para sostener que la cultura es la tercera dimensión para explicar el desarrollo económico junto con el Estado y el mercado. En este marco, ella asume que los valores son un elemento esencial en las relaciones de confianza porque, a través del uso de símbolos compartidos, estos generan una intersubjetividad social entre socios (Braithwaite, 1998; Hardy, Phillips et al. 1998, citados en Labarca, 2012: 69-70).

Más adelante, Labarca (2012: 113) plantea que los Estados de Chile y China "jugaron un rol crucial en fomentar la confianza en dos maneras complementarias". Primero, en el caso de China, la fuente de confianza es la noción de "mundo armonioso" usada por el gobierno de Hu Jintao. Este concepto habría sido aplicado a las relaciones con América Latina, a través del énfasis en la esfera económica para contener la preocupación de los Estados Unidos sobre la creciente presencia china en la región (Labarca, 2012: 114). Segundo, en el caso de Chile, la confianza sería un elemento de la robusta institucionalidad chilena y su reputación internacional de ser una economía estable y confiable (Labarca, 2012: 127). Teniendo esto en cuenta, Labarca afirma que

Los intereses nacionales han actuado como la fuente primaria que ha conducido la confianza sino-chilena [...] mientras Chile necesitaba a China dado su modelo de crecimiento de orientación exportadora, China requería a Chile en pos de reforzar su discurso benigno hacia la región (Labarca, 2012, pp. 132-133)7.

El hecho de apuntar a que los intereses nacionales son la fuente primaria de la confianza bilateral lleva a Labarca a desarrollar un análisis que, paradójicamente, parece estar inspirado por principios del enfoque positivista racional más que constructivista. Es decir, ella afirma que la confianza tiene una naturaleza calculadora:

Mientras China ha sido motivada por el interés político de tener a Chile como un paso importante dentro de su ofensiva en América Latina, para el segundo China representa el interés de la oportunidad

\footnotetext{
7 Traducción del autor.
} 
dada por el atractivo del mercado chino y la posibilidad de convertirse en un puente entre Asia y América Latina (Labarca, 2012: 133)8.

A su vez, debido a que la confianza tiene una naturaleza calculadora, no es sorpresivo que Labarca destaque la noción del pragmatismo como un elemento fundamental que define a la relación (Labarca, 2012: 140), así como también la noción de poder asimétrico. Mientras Labarca encuentra las fuentes del pragmatismo en la literatura estándar de la relación Chile-China, en el caso del poder asimétrico ella apela a la ciencia política y la economía. Más específicamente, sugiere que la asimetría política estaría manifestada en el consentimiento chileno con la política de una sola China; de lo contrario sus intereses serían seriamente dañados, considerando la dependencia chilena del mercado chino. Mientras que la asimetría económica consistiría en la estructura del comercio bilateral, caracterizado por las importaciones chinas de materias primas y la exportación de productos manufacturados (Labarca, 2012: 145-146).

En esta parte de su estudio, Labarca explica que la narrativa de la confianza entre Chile y China ha sido construida sobre la base de dos mecanismos o procesos. Estos son, primero, la retórica diplomática de los cuatro primeros (Labarca, 2012: 152-155) y, segundo, la creación de una identidad común que ella denomina "China como una identidad de mercado". Ya que la retórica de los cuatro primeros ya ha sido abordada, a continuación, prestaremos atención al segundo mecanismo.

La autora articula esta identidad con el pragmatismo de las políticas exteriores de los dos países, Chile y China. En el caso de esta última, su propia identidad como mercado estaría articulada con la noción de mundo armonioso y la aspiración de decrecer aquellas aprensiones que ven a China como una amenaza (Labarca, 2012: 164). En el caso de Chile, Labarca articula esta identidad con los intereses de los actores nacionales que influyen en la formulación de la política exterior chilena. Es decir, hay ciertos círculos sociales quienes "han actuado conjuntamente en pos de perseguir objetivos similares" en atención a China (Labarca, 2012: 161). En este sentido, no son solo los agentes del estado y del mercado los que han empujado estos intereses, sino que también el círculo académico:

La academia chilena ha privilegiado un enfoque que enfatiza la perspectiva de los negocios más que la de la seguridad o la geopolítica, en tono con la postura oficial chilena [...] Los círculos académicos chilenos han caracterizado al Asia Pacífico, y dentro de esto a China, como una oportunidad económica desde los '90 en adelante influidos

\footnotetext{
8 Traducción del autor.
} 
por la preponderancia neoliberal de la política exterior chilena (Labarca, 2012: 161-162)9 .

En suma, Labarca concluye que la confianza mutua es construida en la medida en que las dos partes tienen políticas exteriores pragmáticas que sostienen las relaciones económicas a través de la interacción de intereses nacionales complementarios y la generación de una narrativa instrumental común. A su vez, porque los intereses nacionales y la narrativa común son el resultado de objetivos racionales e instrumentales, la relación no puede progresar más allá del comercio (Labarca, 2012: 166-169). Como consecuencia de esto, ella propone que la tarea de la construcción de la confianza debe moverse desde el campo de las relaciones interestatales al de los hombres de negocios y corporaciones privadas.

\subsection{Algunas limitaciones del enfoque de las variables soft}

El avance que hace Labarca para la literatura Chile-China es sustancial pues su trabajo marca un quiebre en la forma de estudiar este tema. Una de sus contribuciones más importantes a la literatura es haber formulado un nuevo elemento para explicar la relación sino-chilena. Este elemento es la confianza y su característica central es ser un factor cultural.

Sin embargo, huelga decir que esta autora, a pesar de definir que la confianza es una variable blanda, plantea que ésta tiene una naturaleza calculadora determinada por los intereses nacionales de cada estado. Desde el punto de vista de la teoría de las Relaciones Internacionales, este argumento genera algunos problemas que ameritan ser discutidos.

Primero, aunque Labarca apunta a proponer un novedoso enfoque idealista, es posible observar una paradoja en su problematización por cuanto articula una 'variable cultural suave' con una supuesta 'naturaleza calculadora dura'. Es decir, la paradoja consiste en definir que una variable cultural tiene una naturaleza y que dicha naturaleza está fundada en un discurso materialista que trae al frente nociones como pragmatismo y el poder asimétrico. Este tipo de argumento contradice ciertos principios del constructivismo, el cual es uno de los enfoques en los que esta investigadora se apoya. Siguiendo a Martha Finnemore, por ejemplo, la naturaleza calculadora de la confianza no coincide con la crítica que los constructivistas hacen al positivismo empírico de creer que las prácticas culturales, normas de comportamiento y valores sociales "pueden ser derivados del cálculo de intereses" (Finnemore, 1996: 15).

Segundo, en vez de desarrollar una definición propia de pragmatismo, Labarca usa este concepto como un hecho reificado en la misma manera que lo ha

\footnotetext{
${ }^{9}$ Traducción del autor.
} 
hecho el resto de la literatura. Vale decir, la relación sería pragmática porque artículos previos lo han afirmado, independientemente de si estos artículos han o no definido, explicado o evaluado este concepto en la relación (Domínguez, 2006: 3537; Montalva y Navia, 2007, citados por Labarca, 2012: 140).

Tercero, Labarca aplica el concepto de poder asimétrico de una manera no conclusiva. Ella aborda la asimetría política argumentando sobre la obediencia chilena hacia la política de una sola China. Teoréticamente, el hecho de relacionar esta política china con poder asimétrico implica asumir que China tiene la capacidad y voluntad de constreñir a Chile por cualquier medio de poder, incluyendo el político, militar y el económico (los palos y las zanahorias como diría Nye [2004] en su teoría de poder blando). Desde este punto de vista, más que representar un elemento que está al servicio de un enfoque idealista que critica las variables duras tradicionales, el uso de poder asimétrico nos recuerda al neorrealismo estadounidense que teoriza el concepto de "el ascenso de China", en el cual se retoma el concepto de multipolaridad y se refuerza el carácter anti-idealista de las relaciones internacionales (Mearsheimer, 2014; Waltz, 2000).

\section{Conclusiones}

Este artículo intentó dar cuenta de lo que la literatura ha dicho sobre las causas de la asociación pionera entre Chile y China. Al hacer esto, trajimos al frente las inestabilidades e inconsistencias de estos discursos centrados en las causas materiales, ya que los mismos revelan su irreducible dimensión idealista. Esto es claro cuando prestamos atención a aquellos momentos en los cuales los discursos materialistas del pragmatismo aparecen como incapaces de resolver la frontera entre la ideología de los tecnócratas y su influencia en la política exterior. Los casos de la supuesta desideologización de la elite china, la posibilidad de concebir más pragmatismo que pragmatismo absoluto y la sedimentación de las practicas discursivas que encontramos con el principio de no discriminación y regionalismo abierto son muestras de este vacío explicativo.

Cabe destacar que un argumento común entre los autores es que el éxito de la relación es el resultado de las complementariedades económicas sostenidas sobre los recursos naturales. Tal como Rehner y Montt señalan con un tono de insatisfacción: "hablar de la relación con China hoy todavía significa hablar del cobre" (Rehner y Montt, 2013: 8). De hecho, este tipo de explicación es insatisfactorio para entender la constitución de los compromisos bilaterales pioneros entre Chile y China. El problema que observamos consiste en la imposibilidad de afirmar que los acuerdos pioneros son la mismísima consecuencia del intercambio comercial de recursos naturales. 
Dicho de otro modo, si el mundo material determinara directamente la firma de un tratado de libre comercio, entonces China ya habría firmado este tipo de acuerdo con el resto de sus proveedores de materias primas latinoamericanos (y del mundo). Sin embargo, este no es el caso. Además de Chile, China sólo ha firmado TLCs con Perú y Costa Rica. Además, es posible ver que las relaciones comerciales entre China y el resto de los países han crecido como nunca sin firmar TLCs (Rosales y Kuwayama, 2012). Por último, el argumento sustentado en la causalidad de los recursos naturales elimina toda posibilidad para Chile de ser el país pionero, pues si esa causalidad fuera real, tal como lo asumiría la filosofía de la ciencia positivista, dicho efecto ocurriría simultáneamente con varios países.

Los estudios materialistas caen en cierta incoherencia para explicar la forma en que Chile se volvió el pionero para China. La incoherencia se revela al observar el repetitivo uso de pragmatismo como una idea que se da por sentada para caracterizar la relación en el contexto de las reformas económicas. El hecho de asumir el pragmatismo como una condición objetiva de la relación significa que éste fue despojado de sus orígenes como una auto-interpretación. Así, aunque la tesis del pragmatismo puede ser plausible en ciertas circunstancias, no es posible afirmar que el pragmatismo sea un rasgo constante e inalterable o un elemento que es causado por las reformas económicas.

Aunque algunos estudios han articulado algunas explicaciones basadas en mecanismos causales idealistas, por ejemplo, la creencia en el libre mercado o el entendimiento político generado por las liberalizaciones económicas paralelas, este tipo de causas no han sido estudiadas en profundidad.

Sin embargo, la principal contribución de los enfoques idealistas emergentes es haber sentado la necesidad de pensar acerca de la relación entre el fenómeno de las liberalizaciones económicas paralelas y la asociación pionera entre Chile y China. También ha sentado la necesidad de pensar acerca de la interacción entre la ideología de las elites y sus tecnocracias y su influencia en las políticas exteriores. Cualquier esfuerzo, como los ya emprendidos por Labarca y Montt (2019; Labarca, 2012; Montt, 2014; Rehner y Montt, 2012) para estudiar este tipo de temas significa una novedosa forma de abordar ciertas preguntas que los enfoques materialistas tradicionales no han podido responder satisfactoriamente. En suma, esta tarea permanece como terrenos ontológicos y empíricos inexplorados que merecen ser abordados desde la disciplina de las Relaciones Internacionales. 


\section{Bibliografía}

Allende, S. (1971a): "La "vía chilena al socialismo", Discurso ante el Congreso de la República, 21 de mayo de 1971", en Allende, S., La vía chilena hacia el socialismo. Santiago, Editorial Fundamentos, pp. 27-58.

Allende, S. (1971b): La Política Internacional, en S. Allende, Primer Mensaje del Presidente Allende ante el Congreso Pleno. Santiago, pp. 58-84.

Almeyda, C. y Zhou, E. (1973): Oficio Confidencial. Entrevista del Canciller Almeyda con el Primer Ministro chino Zhou Enlai. Pekin, Palacio del Pueblo 30.01.73.

Ampuero, P. I. (2016): "Diplomacia en transición. La República Popular China frente a la dictadura cívico-militar en Chile", Estudios Políticos, 49, pp. 35-54.

Artaza, M. (2007): "Chile y Asia hoy: una mirada crítica", Estudios Internacionales, 39 (156), pp. 55-65.

Bernal-Meza, R. (2012): "China - MERCOSUR and Chile Relations", en L. Xing y S. F. Christensen, eds., The Rise of China. The Impact on Semi-Periphery and Periphery Countries. Aalborg, Alborg University Press, pp. 59-102.

Bravo, L. M. (2001): "La Inserción Internacional de la República Popular China: Una Visión desde las Relaciones Internacionales", Estudios Internacionales (133), pp. 4870.

Camargo, R. (2013): New critique of ideology: lessons from post-Pinochet Chile. Basingstoke, Palgrave Macmillan.

Cassels, A. (1996): Ideology and international relations in the modern world. Londres; Nueva York, Routledge.

Cui, S. y Z. Zhang (2018): "China y la infraestructura en América Latina desde la perspectiva de la diplomacia económica", en B. Wu, ed., Pensamiento social chino sobre América Latina. Buenos Aires, CLACSO, pp. 261-290.

Dingemans, A. (2014): "East Asia: Chile's Missed Opportunity?", East Asia, 31, pp. 6791.

Domínguez, J. et.al. (2006): “China’s Relations with Latin America: Shared Gains, Asymmetric Hopes”, Inter-American Dialogue, Working Paper. 
Errázuriz, 0. (2006): "Las relaciones de Chile y China: del simbolismo a la acción", Estudios Internacionales, 39(154), pp. 169-178.

Fermandois, J. (1985): "Ideología y pragmatismo en la política exterior chilena durante la crisis del sistema político 1970-1975". Revista de Ciencia Política, 7, pp. 169-178.

Finnemore, M. (1996). National interests in international society. Ithaca, Cornell University Press.

Garretón, M. A. (2012): Neoliberalismo corregido y progresismo limitado: los gobiernos de la Concertación en Chile, 1990-2010. Santiago, Editorial Arcis.

Harris, R. L. (2015): Understanding China's Relations with the Latin American and Caribbean Countries Research Notes. Latin American Perspectives, 42(205), pp. 2741.

Heine, J. (2006): "China, Chile and free trade agreements", Estudios Internacionales, 38(152), pp. 143-147.

Jiang, S. (2001): "Relaciones bilaterales Chino-Chilenas. Al umbral del nuevo siglo", Estudios Internacionales, 34 (133), pp. 12-36.

Jiang, S. (2006): "Recent Development of Sino-Latin American Relatios and Its Implications", Estudios Internacionales, 38 (152), pp. 19-41.

Kaiser, A. (2009): La fatal ignorancia: la anorexia cultural de la derecha frente al avance ideológico progresista. Santiago, Instituto Democracia y Mercado.

Kissinger, H. y Zhou, E. (1973): Memorandum of Conversation. Top Secret/Sensitive (Declassified). November 13th 1973. Washington. Disponible en web: https://nsarchive2.gwu.edu/nsa/publications/DOC readers/kissinger/docs/index.ht $\underline{\mathrm{ml}}$

Labarca, C. y M. Montt (2019): "Discurso como representación de sentido en las relaciones internacionales: el caso sino-chileno", Estudios Políticos, 47, pp. 163-184.

Labarca, C. (2009): "El capitalismo confuciano en la era de la globalización: nuevas bases para construir xinyong y guanxi - Lecciones para Chile", Estudios Internacionales, 163, pp. 23-46. 
Labarca, C. (2012): A model for trust building: The state, market, and cultural norms in Sino-Chilean economic exchange. Tesis Doctoral, Durham University, Durham. Disponible en web: http://etheses.dur.ac.uk/3539/

Labarca, C. (2013): "Identity and Institutionalisation as Trust Building Strategies: The Sino-Chilean Case", Revista de Ciencia Política, 33 (2), pp. 489-511.

Labarca, C. (2015): Ni hao Mr. Pérez, buenos días Mr. Li. Chile y China: Cultura, negocios y confianza en la era global. Santiago, Ediciones UC.

Li, J. (2011): "Heredando la bella tradición del pasado para crear un futuro promisorio", en Y. T. Lee y H. Wu, eds., Chile y China: cuarenta años de política exterior. Una trayectoria de continuidad y perseverancia. Santiago, RIL Editores, pp. 161-166.

Matkovic, B. (2016): China y Chile: análisis de la relación en el contexto del orden internacional liberal (2005-2015). Grado de Licenciada en Estudios Internacionales, Universidad de Santiago de Chile, Santiago.

Matta, J. E. (1991): "Chile y la República Popular China 1970 - 1990", Estudios Internacionales, 24(95), 347-367.

Mearsheimer, J. J. (2014): The Tragedy of Great Power Politics. Nueva York, W.W. Norton y Company, Inc.

Ministerio de Relaciones Exteriores de la República Popular China (2016): Documento sobre la Política de China Hacia América Latina y el Caribe. Beijing. Disponible en web: http://www.fmprc.gov.cn/esp/zxxx/t1418256.shtml

Montalva, J. D. y P. Navia (2007): "Chile and China: Building Relations Beyond Trade?", China-Latin America Task Force, 14, pp. 1-14.

Montt, M. (2014): "Representaciones de China en las Américas y la Península Ibérica", China Review International, 21(3/4), pp. 257-262.

Moreno, A. (2011): "Intervención del Canciller Moreno en Workshop 'Los Principales Países y Economías de Asia Pacífico en Chile' - 10a Versión", 19 de mayo de 2011, Santiago. Disponible en web:

https://minrel.gob.cl/minrel/site/artic/20110519/pags/20110519161708.html 
Moulian, T. (1997): Chile actual: anatomía de un mito. Santiago, Universidad ARCIS; LOM.

Muñoz, H. (1986): Las relaciones exteriores del gobierno militar chileno. Santiago, PROSPEL-CERC; Ediciones del Ornitorrinco.

Niu, H. (2018): "La mejora de la cooperación general con América Latina y el Caribe", en B. Wu, ed., Pensamiento social chino sobre América Latina. Buenos Aires, CLACSO, pp. 217-237.

Nye, J. S. (2004): Soft Power: The Means to Success in World Politics. Nueva York, Public Affairs.

Pinedo, J. (1997): "Chile a fines del siglo XX: entre la modernidad, la modernización y la identidad", Universum, 12, pp. 1-40.

Pérez Le-Fort, M. (2006): "Relaciones sino-chilenas bajo nuevas circunstancias", Estudios Internacionales, 38 (152), pp. 123-136.

Rehner, J. y M. Montt (2012): ""Distancia cultural" entre América Latina y Asia. Reflexiones sobre el uso y utilidad de dimensiones culturales", en Documentos de Trabajo en Estudios Asiáticos, 8, Serie Pensamiento y Cultura. Santiago, Pontificia Universidad Católica de Chile.

Rehner, J. y M. Montt (2013): "Reflexiones para una discusión estratégica de la relación futura de Chile con la República Popular China", en Documentos de Trabajo en Estudios Asiáticos, 10, Serie cooperación y conflicto. Santiago, Pontificia Universidad Católica de Chile.

Rodríguez, I. (2011): "Chile y China: 40 años de relaciones de cooperación y amistad", en T. L. Yun y H. Wu, eds., Chile y China: cuarenta años de política exterior. Una trayectoria de continuidad y perseverancia. Santiago, RIL Editores, pp. 167-208

Rodríguez, I. y D. Leiva (2013): "El soft power en la política exterior de China: consecuencias para América Latina", Polis Revista Latinoamericana, 12 (35), pp. 497517.

Rodríguez, I. y Y. Shouguo, eds. (2013): "La diplomacia pública de China en América Latina: lecciones para Chile". Santiago: RIL editores. 
Rosales, 0. y Kuwayama, M (2012) "China y América Latina y el Caribe. Hacia una relación económica y comercial estratégica", Santiago, Libros de la CEPAL.

Ross, C. (2007a): "Chile y el Asia Pacífico: La construcción histórica del futuro", Si Somos Americanos. Revista de Estudios Transfronterizos, 9 (1), pp. 109-140.

Ross, C. (2007b): Chile y Japón, 1973-1989: de la incertidumbre a la alianza estratégica. Santiago, LOM; USACH.

Schuschny, A., J. Durán Lima y C. De Miguel (2008): "Política comercial de Chile y los TLC con Asia: evaluación de los efectos de los TLC con Japón y China", en Serie Estudios Estadísticos y Prospectivos, 66.

Schmidt, F. (2011): "Relaciones Chile - China: 40 años", en T. L. Yun y H. Wu, eds., Chile y China: cuarenta años de política exterior. Una trayectoria de continuidad y perseverancia. Santiago, RIL Editores, pp. 95-159.

Soto, A. (1998): "Chile mira hacia China. Relaciones en una nueva era", Estudios Internacionales, 31(121-122), pp. 37-53.

Sun, Y. (2011): "Retrospectiva y reflexión sobre los cuarenta años de relaciones sinochilenas", en Y. T. Lee y H. Wu, eds., Chile y China. Cuarenta años de política exterior: Una trayectoria de continuidad y perseverancia. Santiago, RIL Editores, pp. 225-242.

Toloza, C., ed. (2015): De los Andes a la Gran Muralla. 45 años de relaciones entre Chile y China. Valparaíso, Andros; Biblioteca del Congreso Nacional de Chile.

Uribe, A. (2016): Memorias para Cecilia. Santiago, Lumen.

van Klaveren, A. (1997): "América Latina: hacia un regionalismo abierto". Estudios Internacionales, 30(117), pp. 62-78.

van Klaveren, A. (2006): "Chile: hacia un multilateralismo efectivo", Estudios Internacionales, 39(153), pp. 133-145.

van Klaveren, A. (2011): "La política exterior de Chile durante los gobiernos de la Concertación (1990-2010)", Estudios Internacionales, 44(169), pp. 155-170.

Waltz, K. N. (2000): "Structural Realism after the Cold War", International security, 25(1), pp. 5-41. 
Wang, H. (1998): "Contemporary Chinese Thought and the Question of Modernity". Social Text, 55, pp. 9-44.

Wang, H. (2009): The End of the Revolution. China and the Limits of Modernity. Londres, Verso.

Wilhelmy, M. y R. M. Lazo (1997): "La política multilateral de Chile en Asia-Pacífico". Estudios Internacionales, 30(117), pp. 3-35.

Wu, B., ed. (2018): Pensamiento social chino sobre América Latina. Buenos Aires, CLACSO.

Wu, H. (2011). "Las relaciones sino-latinoamericanas y la política exterior de China hacia la región", en Y. T. Lee Cheng y H. Wu, eds., Chile y China. Cuarenta años de política exterior: Una trayectoria de continuidad y perseverancia. Santiago, RIL Editores, pp. 73-94.

Xin, X. (2018): "El acoplamiento de las estrategias de desarrollo económico entre China y América Latina y el Caribe", en B. Wu, ed., Pensamiento social chino sobre América Latina. Buenos Aires, CLACSO, pp. 239-260.

Xu, Y. (2003): "The debates between liberalism and the new left in China since the 1990s", Contemporary Chinese Thought, 34(3), 6-17.

Yang, S. (2011): "Perspectivas y algunas reflexiones sobre el desarrollo de las relaciones sino-chilenas", en Y. T. Lee y $\mathrm{H}$. Wu, eds., Chile y China: cuarenta años de política exterior: Una trayectoria de continuidad y perseverancia. Santiago, RIL Editores, pp. 209-224

Yu, Y. (2006): "Comments on the Free Trade Agreement between China and Chile", Journal of Latin American Studies, 6.

Zhang, X. (2006): "El entendimiento sobre el Tratado de Libre Comercio entre China y Chile", Estudios Internacionales, 38 (152), pp. 113-121.

Fecha de recepción: 2 de marzo de 2020

Fecha de aceptación: 20 de abril de 2020 